\title{
MUDRA: Strengthening Institutional Finance for Micro Enterprises
}

\author{
Ganesh Kumar \\ Department of Economics, Army Cadet College, Indian Military Academy, Dehradun, India \\ Corresponding author: saini_ganesh@rediffmail.com
}

\begin{abstract}
The MSME plays a vital role in providing large employment opportunities at comparatively lower capital than large scale industries. It also helps in industrialization of rural and backward areas and assuring more equitable distribution of national income and wealth. However this sector is continuously facing many challenges and the biggest bottleneck to this sector is the weak institutional financial support. Therefore, in order to provide more institutional finance to the sector, "funding the unfunded" and promote entrepreneurship and self employment in the country government need a specialized financial institution. Thus, Government has created MUDRA. The main objectives of MUDRA are to create an inclusive, sustainable and value based entrepreneurial culture for achieving economic success and financial security and more income and employment opportunities which are the preconditions for inclusive growth. Through establishment of MUDRA, this sector can be used an important tool to achieve financial inclusion and inclusive growth. MUDRA provides refinance support to banks and MFIs for lending to micro units having loan requirements up to ₹ 10 lakh.
\end{abstract}

Keywords: MUDRA, Formal Sources of fund, Non- Corporate Small Business Sector

The economic and social importance of Micro, Small and Medium Enterprises (MSME) sector is a well accepted fact. This sector is an important tool not only for inclusive growth and sustainable development but also for social and political stability in a country. The sector plays a crucial role in providing large employment opportunities at comparatively lower capital than large industries. It also helps in industrialization of rural and backward areas, thereby, reducing regional imbalances, assuring more equitable distribution of national income and wealth. The MSME sector of India is highly heterogeneous in terms of the size of the enterprises, variety of products and services, and levels of technology. This sector is a significant component of India's growth story, making significant contribution to GDP, employment and export. Currently, this sector contributes 37.5 percent of India's GDP, 45 percent to the manufacturing output and around 40 percent to export, both directly and indirectly.
A dynamic global economic scenario has thrown up various opportunities and challenges to this sector. The sector is continuously facing challenges like shortages of funds, limited access to equity capital, technological obsolescence and lack of infrastructure facilities. Although, since independence various initiatives have been taken to encourage this sector but the sector is still witnessing several challenges in terms of access to finance. The biggest bottleneck to this sector is the weak institutional financial support. Moreover, the majorities of these enterprises are informal and unregistered which have not been covered by the formal banking sector. Further, one of the most persistent problems that Indian economy is facing is the inequitable distribution of finance. The larger portion of finance is available to the bigger companies whereas MSME sector is receiving too little capital. The commercial banks and other development financial institutions are hesitant to provide enough financial support to this sector. 
Within MSME, Micro enterprises occupied an important place and they are facing more serious problem to avail finance from formal banking system. Thus, this sector requires a supportive financial policy framework. Several policy, regulation and institutional initiatives have been taken to promote availability of finance to MSME. In order to remove all problems related to finance for Micro \& Small enterprise, Government has created Micro Units Development \& Refinance Agency Ltd. (MUDRA). MUDRA has been setup as a refinancing agency for last-mile Financial Institutions such as Banks, Microfinance Institutions (MFIs) and Non-Banking Financial Companies (NBFCs) that extend credit to Micro enterprises engaged in manufacturing, trading or services, whose credit requirements are up to ₹ 10 lakh. The main objectives of MUDRA are to create an inclusive, sustainable and value based entrepreneurial culture for achieving economic success and financial security and more income and employment opportunities which are preconditions for inclusive growth. Through establishment of MUDRA, this sector can be used an important tool to achieve financial inclusion and inclusive growth.

\section{Need for specialized financial institutions for development of NCSBS}

As per NSSO Survey (2013), there are around 5.77 crore small/micro units in the country, engaging around 12 crore people, mostly individual proprietorship. These units engaged in manufacturing, processing, trading and service sector and referred as NonCorporate Small Business Sector (NCSBS). Over 60 percent of NCSBS units are owned by persons belonging to scheduled caste, scheduled tribe and other backward castes. Most of these units are outside from the formal banking system to avail finance, and hence are forced to borrow from informal sources of finance. Only 4 percent of such units get finance from formal sources of finance. Providing access to institutional finance to such units would turn them into strong instrument for inclusive growth. Therefore, in order to provide institutional finance to these units, "funding the unfunded" and promote entrepreneurship and self employment in the country government need a specialized financial institution. Thus, government established MUDRA as a subsidiary of SIDBI on $8^{\text {th }}$ April 2015.
It is well established that finance is the life blood of the process of economic and social development of a country. The provision of finance acts as pump-primer, especially when it flows through financial institutions. The basic objective of this paper is to study the role of MUDRA in providing the institutional finance for micro units of NonCorporate Small Business Segment (NCSBS) and challenges before MUDRA. The present paper is based on secondary data collected from the annual report of MUDRA and divided in three sections. The first section 'Introduction' deals with the highlights of the importance of MSME/ NCSBS in Indian economy, review of literature need for creations of MUDRA and responsibilities assigned to MUDRA. The second Section deals with the study of various MUDRA schemes and programe for the development of Micro enterprises analyse the performance of Pradhan Mantri Mudra Yojana (PMMY) and challenges before MUDRA. The last section concludes the study with some important suggestions.

\section{REVIEW OF LITERATURE}

Ajit Kanitkar (1994) in his study discussed the emergence and sustenance of micro entrepreneur in rural India and identifies the factors which are facilitated entry of the village based agriculture entrepreneurs into a business activity or nonfarm based activity. Annapurna Shaw (1990) examines the interaction and linkage between the large scale, small scale and informal sector of an important industrial region of Maharashtra and concludes that these sectors are complementary to each other. Kamal Nayan Kabra (2003) in his work conducts the comparative study of organised sector and unorganised sector of India and shows that unorganised sector of India is large and has significant place in the economy, even though it is relatively neglected sector in the arena of public policy support and academic discourse. He suggests some potential approaches which can help the unorganised sector move towards attain the rightful place in the economy. Prashant Salwan (2012) point out that as MSMEs did not adopt the best management practices and due to some other reason their financial position are very weak so that they are not capable to repay the loan. Therefore, Non Performing Assets of Banks are increased; as 
a result banks are not interested to give loan to this sector. Vanish Kathuria, Rajesh Raj S.N. and Kunal Sen et al. (2010) analyse the production performance of organised sector and unorganised sector of the Indian manufacturing sector during the period from 2000-01 to 2004-05. This study concludes that labour productivity has increased for the organised sector whereas both labour productivity and capital intensity growth have slow down in the unorganised sector. Rama Krishan (1962) highlighted the problem of finance of small scale industries. He visualizes the vicious circle of capital deficiency and resources in small scale industries. According to him, credit will come only when capital is there. In other words, capital is the basis to borrowings. He observed that, the commercial banks and financial institutions are hesitant in granting loans to these industries, because weak capital base of the small scale industries. Balu (1991) analyses the various sources of finance available to entrepreneurs for initial capital, term loans and working capital and the various problems faced by them on financial front. He observed that majority of the entrepreneurs felt that though banks and financial institutions lend money they also generate various problems like delay in sanction and disbursement, inadequacies of loan, impersonal and target attitudes of the officials on blocking the way of development. Thus his study recommended the establishment of a single lending agency which can provide quick and timely services to the entrepreneurs. Salvi and Pethe (1997) according to this studied that development banks play an important role in the process of industrialization of the country.

In under developed countries like India the process of industrialization has been retorted due to lack of various ingredients, such as capital, modern technology, industrial infrastructure etc. to help to overcome these obstacles and to supply missing ingredients development banks play a crucial role. Narta and Sharma (1997) in their work pointed out that finance is the lubricant of the process of economic growth. When finance is made available, industrial activities can be initiated, which give rise to new investment opportunities towards industrialization. Jaitley Arun (2017) assumed that it is fact that people in the unorganised sector are much higher than the organised sector, but the former gets credit with a lot of difficulty. If the resources of banks and financial institutions through various schemes are diverted towards unorganised sector, it will help create more employment.

\section{Responsibilities assigned to MUDRA}

In order to achieve the objectives of creation of MUDRA government assigned following responsibilities to MUDRA:

1. Laying down policy guidelines for micro/ small enterprise financing business.

2. Registration, regulation, supervision and required accreditation of MFI entities.

3. Laying down responsible financing practices to ward off over indebtedness and ensure proper client protection principle and methods of recovery.

4. Development of standardized set of covenants governing last mile lending to micro/ small enterprise and promoting right technology solution for financial delivery to the last mile.

5. Formulating and running a credit guarantee scheme for providing guarantee to the loans which are being extended to micro enterprise by Banks, NBFCs and MFIs.

6. Creating a good architecture of last mile credit delivery to micro business under the scheme of PMMY.

7. All necessary supporting development and promotional activities for all stake holders of MUDRA.

\section{Section Two}

\section{MUDRA Scheme \& Programe for Micro Enterprises development}

The basic objective of formation of MUDRA is to provide finance and other related services to micro units directly and indirectly and creating an environment in which these units prove an important tool for inclusive growth and sustainable development of country. To achieve these objectives MUDRA develop many schemes and programmes. These programmes and schemes are as follows:

\section{Pradhan Mantri Mudra Yojana (PMMY)}

MUDRA provides refinance support to banks and MFIs for lending to micro units having loan 
requirements upto $₹ 10$ lakh. It provides refinance to micro business under the scheme of the PMMY. Under this scheme, on the basis of stage of growth and need of finance of these units, MUDRA has divided micro units into three categories to provide finance. These three categories are namely 'Shishu', 'Kishor' and 'Tarun'. Category Shishu would cover loans up to ₹ 50 thousand, Kishor would cover loans from fifty thousand to five lakh and category Tarun would cover from five lakh to ten lakh. Further, it would be ensured that more focus is given to Shishu Category Units than Kishor and Tarun Categories. Thus, this scheme is designed keeping in view of all characteristics of NCSBS, accordingly all these units get proper opportunities for development. The funding support from MUDRA are of various types like 'Micro Credit Scheme' for MFIs, 'Refinance Scheme for banks', 'Women Enterprise Programme' for women economic empowerment and 'Securitization of loan Portfolio' for strengthening the financial position of institutions providing finance for micro enterprise and 'MUDRA Card'. MUDRA Card is an innovative product which provides working capital facility as a cash credit arrangement. Actually it is a debit card issued against the MUDRA loan account, for working capital portion of the loan. The basic purpose of this card is to provide flexibility and easy accessibility of finance. By this card borrower can use loan amount in most efficient manner and keep the interest burden minimum.

\section{Development and Promotional Support provided by MUDRA:}

In addition the fund constraints, the NCSBS face many non-fund challenges, like skill development gap, knowledge gap, information asymmetry, financial / business literacy and lack of growth orientation. To conquer these constraints, MUDRA will adopt a credit-plus approach and offer development and support services to the target units. It will act as a market maker and build up a network with capacities to deliver all services in an efficient and sustainable way. MUDRA schemes and programmes are imparting financial and business literacy to NCSBS which are the pre conditions for the development of micro sector in modern era and providing all required support for last mile financiers.

\section{Performance of PMMY}

Category-wise number of loan accounts, amount of loan sanctioned and disbursed by MUDRA during 2015-16 have been presented in Table 1. It is evident from the table that total number of loan account are $3,48,80,924$ in which category Shishu, Kishor and Tarun are 3,24,01,046 (92.89\%), 20,69,461(5.93\%) and $4,10,417(1.18 \%)$ respectively. Further, the total amount of loan sanctioned and disbursed to all categories are ₹ 1,37,449.27 crore and ₹ 1,32,954.73 crore respectively. It is clear from the table that out of total amount disbursed ₹ 62027.69 (46.65\%) crore is for Shishu category, whereas ₹ 41073.28 crore (30.89\%) in Kishor category and ₹ 29853.76 Crore $(22.45 \%)$ in Tarun category. The ratio of total amount of loan disbursed to total amount of loan sanctioned is 0.967 while in case of Shishu, Kishor and Tarun category it is $0.986,0.954$ and 0.947 respectively.

Types of micro unit wise number of account, amount of loan sanctioned and disbursed by MUDRA during 2015-16 have been presented in Table 2. It is evident from the table that out of total number of accounts 2,76,28,265 (79.21\%) are women borrowers but in the case of loan amount disbursed to these units are only ₹ $63190.43(47.53 \%)$ crore followed by new entrepreneurs and minority units. Table 2 shows that only 11.72 percent of loan accounts and 10.20 percent of loan amount disbursed to entrepreneurs belong to minority communities. Further, 2417219 units availing loan used overdraft facility against their PMJDY accounts. The amount under this overdraft facility is only ₹ 274.02 crore. It is also clear from the table that 5,17,456 MUDRA card are issued for sanctioned amount of ₹ 1476.96 crore and ₹ 1391.25 crore are withdrawn by the borrowers.

Institution wise loan account open and amount of loan disbursed under this scheme have been presented in Table 3. It is evident from the table the highest number of accounts 23050447 (66.08\%) are opened in NBFC- Micro Finance Institutions followed by Public Sector Commercial Banks, Private Sector Commercial Banks, Regional Rural Banks, SBI and Associates Banks, Micro Finance Institutions and Foreign Banks are 5306988 (15.21\%), 3067686 (8.79\%) 1410787 (4.04\%), 1300589 (3.73\%), $743980(2.13 \%)$ and $447(0.001 \%)$ respectively. While in the loan amount disbursed NBFC-Micro Finance 
Table 1: Categories-wise Loan Amount Sanctioned and Disbursed by MUDRA during 2015-16 (Amount ₹ in crore)

\begin{tabular}{ccccc}
\hline Category & No. of A/c & Sanctioned Amt. & Disbursed Amt. & Disbursed/Sanctioned \\
\hline Shishu & $32401046(92.89)$ & $62894.96(45.76)$ & $62027.69(46.65)$ & 0.986 \\
Kishor & $2069461(5.93)$ & $43052.55(31.32)$ & $41073.28(30.89)$ & 0.954 \\
Tarun & $410417(1.18)$ & $31501.76(22.92)$ & $29853.76(22.45)$ & 0.947 \\
\hline Total & $34880924(\mathbf{1 0 0})$ & $\mathbf{1 3 7 4 4 9 . 2 7 ( 1 0 0 )}$ & $\mathbf{1 3 2 9 5 4 . 7 3 ( \mathbf { 1 0 0 } )}$ & $\mathbf{0 . 9 6 7}$ \\
\hline
\end{tabular}

Note: Figures in parentheses are percentage of total; Sources: MUDRA: Annual Report 2015-16.

Table 2: Micro Unit-wise Loan Amount Sanctioned and Disbursed by MUDRA during 2015-16 (Amount ₹ in crore)

\begin{tabular}{cccccc}
\hline S1. No. & Types of Micro Unit & No. of account & $\begin{array}{c}\text { Total amount sanctioned } \\
\text { under all Categories }\end{array}$ & $\begin{array}{c}\text { Total amount disbursed } \\
\text { under all Categories }\end{array}$ & $\begin{array}{c}\text { Disbursed / } \\
\text { Sanctioned }\end{array}$ \\
\hline 1 & Women Entrepreneurs & $27628265(79.21)$ & $82183.55(59.79)$ & $63190.43(47.53)$ & 76.89 \\
2 & New Entrepreneurs & $12474668(35.76)$ & $61649.95(44.85)$ & $58908.08(44.31)$ & 95.55 \\
3 & Minority & $4088210(11.72)$ & $14017.99(10.19)$ & $13560.3(10.20)$ & 96.73 \\
4 & PMJDY OD account & $2417219(6.91)$ & $448.49(0.33)$ & $274.02(0.21)$ & 61.09 \\
5 & MUDRA Card & $517456(1.48)$ & $1476.96(1.07)$ & $1391.25(1.05)$ & 94.20 \\
6 & Skill Trained Persons & $1906475(5.46)$ & $3640.84(2.65)$ & $3514.26(2.64)$ & 96.52 \\
\hline
\end{tabular}

Note: Figures in parentheses are percentage of total; Sources: MUDRA: Annual Report 2015-16.

Table 3: Institutions -wise Loan Amount Disbursed by MUDRA during 2015-16 (Amount ₹ in crore)

\begin{tabular}{cccc}
\hline S1. No. & Institutions & No. of account & $\begin{array}{c}\text { Total amount disbursed under all } \\
\text { Categories }\end{array}$ \\
\hline 1 & NBFC- Micro Finance Institutions & $23050447(66.08)$ & $44026.06(33.11)$ \\
2 & SBI and Associates & $1300589(3.73)$ & $16999.82(12.79)$ \\
3 & Public Sector Commercial Banks & $5306988(15.21)$ & $39127.28(29.43)$ \\
4 & Private sector Commercial Banks & $3067686(8.79)$ & $20025.65(15.06)$ \\
4 & Foreign Banks & $447(0.001)$ & $21.34(0.016)$ \\
5 & Regional Rural Banks & $1410787(4.04)$ & $10876.22(8.18)$ \\
6 & Micro Finance Institutions & $743980(2.13)$ & $1878.36(1.41)$ \\
\hline & Total & $\mathbf{3 4 8 8 0 9 2 4 ( 1 0 0 )}$ & $\mathbf{1 3 2 9 5 4 . 7 3 ( 1 0 0 )}$ \\
\hline
\end{tabular}

Note: Figures in parentheses are percentage of total; Sources: MUDRA: Annual Report 2015-16.

Table 4: State -wise Loan Amount Disbursed by MUDRA during 2015-16 (Amount ₹ in crore)

\begin{tabular}{cccccc}
\hline S1. No & State / UT & No. of Account & $\begin{array}{c}\text { Percentage of total } \\
\text { account }\end{array}$ & $\begin{array}{c}\text { Disbursed } \\
\text { amount }\end{array}$ & $\begin{array}{c}\text { Percentage of total } \\
\text { amount disbursed }\end{array}$ \\
\hline 1 & Andaman and Nicobar Islands & 24719 & 0.07 & 212.78 & 0.16 \\
2 & Andhra Pradesh & 795688 & 2.28 & 5790.79 & 4.36 \\
3 & Arunachal Pradesh & 4625 & 0.01 & 71.62 & 0.05 \\
4 & Assam & 427272 & 1.22 & 1728.46 & 1.30 \\
5 & Bihar & 2451439 & 7.03 & 7265.91 & 5.46 \\
6 & Chandigarh & 22605 & 0.06 & 204.52 & 0.15 \\
7 & Chhattisgarh & 639711 & 1.83 & 2156.14 & 1.62
\end{tabular}




\begin{tabular}{|c|c|c|c|c|c|}
\hline 8 & Dadar and Nagar Haveli & 1236 & 0.00 & 21.27 & 0.02 \\
\hline 9 & Daman and Diu & 1109 & 0.00 & 12.02 & 0.01 \\
\hline 10 & Delhi & 394388 & 1.13 & 2857.97 & 2.15 \\
\hline 11 & Goa & 45471 & 0.13 & 376.04 & 0.28 \\
\hline 12 & Gujarat & 1086407 & 3.11 & 5910.02 & 4.45 \\
\hline 13 & Haryana & 745535 & 2.14 & 3152.62 & 2.37 \\
\hline 14 & Himachal Pradesh & 85564 & 0.25 & 965.7 & 0.73 \\
\hline 15 & Jammu and Kashmir & 57974 & 0.17 & 1152.15 & 0.87 \\
\hline 16 & Jharkhand & 872868 & 2.50 & 2845.66 & 2.14 \\
\hline 17 & Karnataka & 4459609 & 12.79 & 16469.43 & 12.39 \\
\hline 18 & Kerala & 830411 & 2.38 & 4727.38 & 3.56 \\
\hline 19 & Lakshadweep & 740 & 0.00 & 5.35 & 0.00 \\
\hline 20 & Madhya Pradesh & 2511191 & 7.20 & 7769.29 & 5.84 \\
\hline 21 & Maharashtra & 3535065 & 10.13 & 13372.42 & 10.06 \\
\hline 22 & Manipur & 24021 & 0.07 & 120.03 & 0.09 \\
\hline 23 & Meghalaya & 19151 & 0.05 & 162.41 & 0.12 \\
\hline 24 & Mizoram & 7772 & 0.02 & 77.78 & 0.06 \\
\hline 25 & Nagaland & 5134 & 0.01 & 76.54 & 0.06 \\
\hline 26 & Odisha & 2343261 & 6.72 & 5436.26 & 4.09 \\
\hline 27 & Pondicherry & 82866 & 0.24 & 331.91 & 0.25 \\
\hline 28 & Punjab & 653973 & 1.87 & 3484.49 & 2.62 \\
\hline 29 & Rajasthan & 1159819 & 3.33 & 5248.28 & 3.95 \\
\hline 30 & Sikkim & 6889 & 0.02 & 54.61 & 0.04 \\
\hline 31 & Tamil Nadu & 4781567 & 13.71 & 15496.86 & 11.66 \\
\hline 32 & Telangana & 400761 & 1.15 & 3694.34 & 2.78 \\
\hline 33 & Tripura & 68146 & 0.20 & 337.26 & 0.25 \\
\hline 34 & Uttra Pradesh & 3345382 & 9.59 & 11880.93 & 8.94 \\
\hline 35 & Uttarakhand & 360007 & 1.03 & 1745.08 & 1.31 \\
\hline 36 & West Bengal & 2628548 & 7.54 & 7740.41 & 5.82 \\
\hline Total & & 34880924 & 100 & 132954.73 & 100.00 \\
\hline
\end{tabular}

Sources: MUDRA: Annual Report 2015-16.

Institutions continue to be at first position with 33.11 percent of total loan amount disbursed followed by Public Sector Commercial Banks (29.43\%), Private Sector Commercial Banks (15.03\%) and SBI and Associates Banks (12.79\%).

State/Union Tertiary wise loan account opened and amount of loan disbursed under PMMY have been presented in Table 4 . It is observed from the same table that number of accounts opened under PMMY are highest in Tamil Nadu (13.71\%) followed by Karnataka (12.79\%), Maharashtra (10.13\%), Uttar Pradesh (9.59\%) West Bengal (7.54\%) and Madhya Pradesh (7.20\%). Similarly, in terms of amount of loan disbursed is highest in Karnataka (12.39\%) and followed by Tamil Nadu (11.66\%), Maharashtra (10.06\%), Uttra Pradesh (8.94\%), Madhya Pradesh (5.84\%) and West Bengal (5.82\%).

\section{Section-Three}

\section{Challenges before MUDRA}

Establishment of MUDRA may emerge as a powerful instrument for inclusive growth and financial inclusion. It will significantly increase the confidence in young, skilled, semi skilled and unskilled workers who want to become first generation entrepreneurs and providing required facilities to existing NCSBS who want to expand their activities. There is no doubt in the fact that MUDRA may prove a vital tool for inclusive growth and turn into a game changer, however at the same time it may face various challenges. These challenges are creating obstacles in the suitable expansion of MUDRA and growth of NCSBS. Some of the main possible challenges and risk are as follows: 
The Biggest challenge before MUDRA is its assigned responsibilities and to achieve the objectives which seems to be not only difficult but these will create conflicts in the coming time too. It is observed from the responsibilities assigned to the MUDRA that only it can give solution for the problems faced by micro sector of the economy rather than the other institutions. Is it possible? To provide fund to the micro and small scale sector there are already several number of institutions existing such as SIDBI, NABARD, SFCs and SIDCs etc. in spite of all these existing financial institutions is it right to create a new institution. This means that the already existing institutions were incompetent in achieving their objectives. Will these institutions coordinate with MUDRA or create hindrances in the path of MUDRA. The challenges which these institutions are facing also pose a big challenge in front of MUDRA.

Presently Micro finance institutions are regulated by the RBI. Now MUDRA will also regulate micro finance sector besides RBI which will result in the multiple regulation of micro finance sector. Further MUDRA will be acting as refinance agency and regulation authority, This will in turn affect the function of MUDRA inducing its malfunctioning. MUDRA will provide financial support to NCSBS which are unorganized and unregistered and there is lack of managerial skill and financial / business literacy and they are also facing many challenges. Consequently there is a risk of fraud and uncertainty in this sector creating a doubt of non-recovery of loan means a great threat to the main objective of MUDRA and to the economy of the country.

At present in India only four percent of micro units are getting finance from the formal sources of finance. Thus, MUDRA is created to provide formal finance of remaining 96 percent units; which is also big challenge for MUDRA. In many other countries it is observed that the government uses the country's wealth and means through these types of banks for enhancing their political powers. These types of banks extend loan to the common man on very minimum interest rate which are later forgiven by the government. This creates a doubt of the political gain by the politicians through these schemes in future. It is also a challenge before MUDRA.

In addition prevailing corruption is a serious threat to it. It is well established that the largest contributors to the corruption are entitlement programs and social spending schemes enacted by the Indian government. It is going to provide finance for unregistered and unorganized sector and banks are liberal for providing the loan to micro sector. All these issues may encourage the corruption. The Indian banking sector has already been facing multiple challenges in recent times, few of them are non-performing assets, decaline profits, financial exclusion, poor governess, and crisies of management, corruption and external pressure for implementation of Basel norms. The performance of PMMY during 2015-16 reflects that like other schemes of government, regional imbalance can be one of the challenges for this sector also.

\section{CONCLUSION}

The MSME sector is recognized as key facilitators for socio economic development of the country and considered as an important tool for inclusive growth, but sector is witnessing several challenges in general and access to finance in particular. Therefore, in order to eliminate all problems related to availability of formal finance, government of India created MUDRA. The basic objective of MUDRA is to provide or divert required fund from formal financial sources to MSME/NCSBS. The idea of MUDRA is not just to provide finance to NCSBS, actually it is to offer credit plus approach in which access to credit will be combined with various entrepreneurship and socio economic development services. Funding the unfunded units is the core purpose that MUDRA provides refinance support to and credit guarantee for these lenders who finance such activities. MUDRA provides refinance support to banks and MFIs for lending to micro units having loan requirements up to ₹ 10 lakh. During 2015-16, PMMY made a significant contribution by extending credit of ₹ 132954.73 crore to 34880924 borrowers under Shishu (46.65\%), Kishor (30.89\%) and Tarun (22.45\%) category. It also helped in extending financial support to women entrepreneurs with ₹ 63190.43 crore and weaker section of the society(Minority) with ₹ 13560.3 crore. It has also facilitated the inclusion of 12474668 new entrepreneurs in formal credit system with providing loan amount of ₹ 58908.08 crore. Under this scheme the highest numbers of accounts are opened in NBFC followed by public sector banks 
and private sector commercial banks. Stare and Union Territory wise performance of PMMY during 2015-16 reflects regional imbalance. The highest numbers of account are opened in Tamil Nadu followed by Karnataka, Maharashtra, Uttar Pradesh, West Bengal and Madhya Pradesh.

There is no doubt that MUDRA may prove a crucial instrument for socio economic development of the country and providing facilities for inclusive growth. However there are some challenges before it. It seems that all these challenges are because government assigned over responsibilities to MUDRA, there are already several working refinancing agencies for providing finance, weak or poor record of government for implementation of this type of schemes which become more serious due to prevailing corruption. Therefore, government will take required measures to deal with these challenges. Over all, MUDRA is a step in right direction for funding the unfunded, although govt shall set up a powerful monitoring and grievance remedy mechanism for the problems arrived under the scheme.

\section{REFERENCES}

Ajit, Kanitkar. 1994. Entrepreneurs and Micro Enterprise in Rural India, Economic and Political weekly, 29(9): M25-M30.

Alok, B Shiram. 2015. MUDRA Bank to "Fund the Unfunded", Employment News, 40(5): 2-8.

Annapurna, Shaw. 1990. Linkages of Large Scale, Small Scale and Informal Sector Industries: a study of Thana-Belapur, Economic and Political weekly, 25(7/8): M17-M22.
Balu, V. 1991. Financing of Small Scale Industries: A Sample Study including notified Backward Areas, Indian Journal of Economics, 72(285): 258-289.

Jaitley, Arun. 2017. Banks Should look at funding Unorganised Sector, The Times of India, July 12, 2017.

Kamal, Nayan Kabra. 2003. The Unorganised Sector in India: Some Issues Bearing on the Search for Alternatives, Social Scientist, 31(11/12): 23-46.

Kumar, Ganesh. 2010. Rural Non-Farm Employment in India: Trends and Issues, Man E Development, 32(4): 91-104.

Kumar, Ganesh. 2013. Financial Inclusion: an Engine of Inclusive Growth, Political Economy Journal of India, 22(1\&2): 38-45.

MUDRA: Annual Report 2015-16

Narta S.S. and Sharma, Devinder. 1997. Industrial Finance in Himachal Pradesh: A Comparative Analysis of Effective Development Banks, Finance India, 11(3): 29-39.

Prashant, Salwan. 2012. Co-Creation: An Exploratory Study of MSMEs \& Large Banks in India, Indian Journal of Industrial Relations, 48(1): 1-18.

Rama, Krishan, K.T. 1962. Financing for Small Scale Industries in India, Asia Publishing House, Bombay.

Salvi and Abhay, Pethe. 1997. Role of Development Banks in the Industrial Development: The Indian Case, Finance India, 11(3): 593-608.

Vanish, Kathuria, Rajesh Raj S.N. and Kunal Sen. 2010. Organised versus Unorganised Manufacturing Performance in the Post Reforms Period, Economic and Political Weekly, 45(24): 55-64.

Vinod, Deshpande. 2015. Mudra Bank: A Game Changer? Yojana, 63(10): 39-41. 